destruction, and that therefore their restitution must be slow or might even be impossible.

4. Microscopical examination of the portions removed previously to suture.-Both the central and peripheral ends of nerves which had not reunited in any way contained young nerve fibres grouped in bundles, each bundle containing, as a rule, many fibres. The fibres contained an axis-cylinder lying in the centre of a clear, well-defined zone, which, again, contained a granular, myeline deposit, while spindle-shaped nuclei were attached to the sides of the fibres at frequent intervals. Where the ends of the nerve were united by a cicatricial segment without conductivity being restored the examination of the segment showed a dense network of connective tissue containing in its meshes bundles of young fibres. The portions excised from the nerves involved at the seat of fracture showed at their central ends a normal structure, but elsewhere no trace of old myeline fibres or of degenerated fibres, but the section was made up of young fibres in bundles, which bundles were of only slightly greater diameter than the old myeline fibres and often surrounded by a delicate sheath. At the point of transition from old to young fibres many of the old myeline fibres contained an enlarged nucleus, with one or two distinct young fibres lodged between the sheath of Schwann and the myeline sheath. In other cases the number of young fibres lying in a similar position was greater. All stages up to complete replacement of the old myeline sheath and axis-cylinder by young fibres were found.

5. Deductions from the microscopical examination.(1) Degeneration.-(a) That there was no evidence of ascending degeneration of the kind described by Krause after interruption of a nerve. (b) That the old axis-cylinder and myeline sheath were destroyed in the peripheral segment and in the ultimate portion of the central segment. (2) Regeneration.-(a) That young nerve fibres were developed in the peripheral segment as well as in the end of the central segment and that even while there was no connexion between the two ends. (b) That these young nerve fibres originated within the old sheath of Schwann from the protoplasm and nucleus of the interannular segment. The spindle-cells formed from the protoplasm and nuclei of interannular segments elongated and united to form protoplasmic threads, with the elongated nuclei attached to their sides. The central portion of the protoplasmic thread developed into the axis cylinder, while myeline was deposited in drops in the protoplasm surrounding the newly formed axis-cylinder. The protoplasm in which the myeline was deposited remained with the nucleus as the neuroblast of the new interannular segment. (c) That so long as conductivity of the nerve was not re-established the development of the fibres proceeded only to a certain stage, and as the new fibres three months and eighteen months subsequently to division presented identical characters this stage might be regarded as a resting stage depending for its further development on re-establishment of function. (d) That cicatricial intercalary segments reuniting the ends of a divided nerve might be permeated by young fibres from end to end without re-establishment of function if the amount of cicatricial connective tissue present in the mass was sufficient by its pressure to prevent the passage of impulses.

Glasgow.

\section{A CASE OF ELEPHANTIASIS SCROTI COM PLICATED BY A LARGE HERNIA; OPERATION; RECOVERY.}

BY W. M. ELLIOTT, M.D. R.U.I., F.R.C.S. EDIN., GOLD COLST MEDICII SERTICE.

THE co-existence of a large scrotal hernia with elephantoid disease of the scrotum is generally regarded as a bar to operative cure of the latter. But a patient afficted with a mass hanging from his pubes to his knees is a burden to himself and generally to his relatives, and he is usually willing to run some risk for the sake of relief. The operation for elephantiasis alone is a simple procedure, but the presence of a hernia in the mass is certainly one of the gravest complications that can occur. Although I have very little hope that the hornia in this case has been permanently cured, still I feel confident that it cannot again acquire its previous bulk, and the patient is at any rate relieved of bis elephantiasis, though at some cost.

The patient, a negro of fine physique, aged about 40 years. was admitted into the Colonial Hospital, Elmina, on June 19th, 1895, with a large scrotal tumour, which appeared to consist of (1) a left inguinal hernia, irreducible, the capacity of the sac being apparentiy over a quart; and (2) elephantiasis scroti with the usual hydrocele of both testes. The tumour hung down to four inches below the knees. 'The patient gave a history of six years' enlargement of the scrotum, but could give no information as to the duration of the hernia apart from the tumour as a whole. The penis was not deeply buried; testicular sensation was present on both sides. The patient was very anxious that something should be done for him and on consultation with my colleague $\mathrm{Mr}$. Murray it was decided to deal with the hernia as a preliminary to amputation of the scrotum.

On July 7th the patient was placed under chloroform and a five.inch incision was made over the hernia. The tissues were carefully diviaded and a few small vessels were taken up; the sac was laid open and was found to be of greater capacity than was expected. The sac wall was very thick. and was composed of strong, tough, white, fibrous tissue. On opening it an unexpected and rather perplexing discovery was made in the shape of a large pink-white glistening masswhich presented somewhat the appearance of a partially distended stomach as seen at a post-mortem examination. This object was about 10 inches long and four inches in diameter, somewhat curved, heavy, and smooth. At each extremity intestine was seen entering or leaving and on percussion two different notes of resonance were produced. The mass evidently consisted of coils of gut agglutinated into one solid piece, presumably by an inflammatory process long extinct. Other coils of normal intestine were also found in the sac. Although the abdominal ring was large enough to admit three fingers the hernial contents were too bulky to be returned through it The original incision, which had previously been extended downwards with a view to ascertaining the exact relations of the large sac, was now extended upwards through Poupart's. ligament into the abdominal wall for about two inches. The incision now measured 11 inches. The contents of the hernial sac were placed in the abdomen with some difficulty, but as the entrance of such a large mass of tissue into a cavity unaccustomed to its presence caused very apparent distension of the abdomen and some appearance of collapse on the part of the patient the judiciousness of the operation was at this stage rather doubtful. The abdominal part of the incision was then closed; the middle third of the sac was detached from its surroundings and removed; and the neck of the sac was twisted and deep sutures were passed through it and the overlying structures. The lower part of the sac which was adherent to the left testis was dropped back into the scrotum and the scrotal incision was closed, a counter opening having been made through the back of the scrotum for drainage purposes. As the result proved, the spermatic cord had been severely handled.

For 11 days after the operation the symptoms were those of progressive toxæmia. At first there were tympanites and abdominal tenderness, which disappeared on the fourth day, and the patient began to exhibit a high temperature, gradual emaciation, a dirty tongue, irregular muscular twitchings, and a profuse foul-smelling, dirty-brown discharge from the posterior scrotal opening. There was much difficulty in keeping the parts clean owing to the large mass which had to be manipulated. The long incision had healed by first intention in its deeper layers and the superficial layers were granulating in a healthy manner. Owing to the serious condition of the patient it was necessary to explore the source of the foul-smelling discharge, and I proceeded to the removal of the scrotal mass. On July 18th a tourniquet was placed round the neck of the tumour, avoiding the penis. On incising the scrotum it was found that the discharge had come from the lower third of the hernial sac which had been left in the scrotum and which had completely necrosed, the necrosis involving also the left testicle. The cord was divided high up and the testicle and sloughing sac were removed. The right testicle and cord were then exposed, the hydrocele (about four ounces) was tapped and the parietal layer of the tonica. vaginalis was removed. A flap was then cut from the right side of the scrotum sufficient to cover the remaining testis, 
the elephantoid mass was amputated, the testis was sutured lightly to the face of the stump and the flap brought over it and secured in place by silver sutures. There was but little arterial hæmorrbage considering the size of the tumour and only a few small arteries required ligature. There was considerable venous bleeding with oozing of lymph from the blubbery elephantoid tissue.

The subsequent history of the case while in hospital is that of the slow healing of the wound and the gradual recovery of the patient from the prostrate condition into which he was thrown by the septicæmia preceding and the loss of blood accompanying the second operation. The healing of a wound made through elephantoid tissue is particularly slow, first intention even under strict asepsis being very rare and even granulations are weak and of slow growth. The scrotal remains gradually contracted in size. The patient slowly recovered strength and was discharged on August 28th, 41 days after amputation of the scrotum, having been in hospital 70 days. McLeod gives from six weeks to two months as the period for healing after amputation without flaps. I am aware that McLeod, the leading authority on the operative treatment of elephantiasis scroti, condemns the flap operation. A few weeks ago I had an opportunity of seeing one of my patients on whom I had performed scrotal amputation by flaps cut from affected tissue 16 months previously. The scrotum which before operation weighed about $60 \mathrm{lb}$. had now contracted to the size of the closed fist, there was no sign of recurrence, the patient's sexual power was restored, and he was on his way to Kumasi as a vovernment carrier with a load of $60 \mathrm{lb}$. on his head. Gold Coast.

\section{THE PREVENTION OF SICKNESS AFTER AN ASTHETICS.}

BY J. BLUMFELD, M.D. CANTAB.

ASSISTANT AVESTHETIST, STT. GEORGE'S HOSPITAL; AYESTHETIST TO THE GROSVENOR HOSPITAL FOR WOMEN AND ÇHILDREN, ETC.

A PATIENT's dread of operation is often due more to his fear of anæsthetics than to that of the operation itself. And his dread of the anæsthetic is not because of its danger, for he is aware that, correctly chosen and skilfully given, it is practically safe, but because of the sickness which he anticipates as an inevitable consequence. Now, after-sickness from anæsthetics is less common than is usually supposed and by careful attention to several details it can be made less common still. Ether is nsually particularly dreaded because of the sickness expected afterwards. Yet the truth is that if the operation takes not much more than 20 minutes the vast majority of patients are not sick at all if the ether is preceded by gas and is given with careful regard to using the smallest possible quantity consistent with good anæsthesia. Moreover, one important point is often overlooked-viz., that the sickness often precedes the return of consciousness. In such a case the patient, of course, experiences no unpleasantness from the sickness and if questioned next day replies that he was not sick at all after the anæsthetic. Attempts to prevent or counteract after-sickness by the use of drugs have hitherto not been encouraging. The drugs that have been chiefly tried-morphia, cocaine, atropine, and chloral-have either not prevented vomiting or have given rise to such alarming symptoms that it is obviously better to run the risk of vomiting than of its remedy. At present it must be admitted that we have no direct antagonist to ether and chloroform in this respect. But the vomiting sometimes caused by these anæsthetics, though it is probably in the main an effect of their action on the brain, is not entirely so, and it is with regard to these other matters also concerned in the causation of the vomiting that we can do a good deal towards its prevention. That much can be done to this end is obvious from the fact that after-sickness is both more frequent and more formidable when the anæsthetic is not administered by someone who has frequent experience in the matter. The reason for this is simple. One of the chief points concerned is the amount of anæsthetic that is used. Now with an inexperienced administrator this is usually too little or too much. If too little the operator has an anxious and uncomfortable time during operation; if too much the patient suffers severely afterwards. There is nothing in the administration of anæsthetics that requires experience more than to know whether to press or to diminish the anresthetic. To know this the administrator must be able to realise the degree of anæsthesia that has been reached. And it is impossible to do this without constant opportunities for observing patients under an anæsthetic. Consequently, misled by some apparent indication of "coming round," the inexperienced administrator pushes the anæsthetic to a needless extent and the patient is proportionately sick afterwards. On the other hand, fears are aroused that the patient is too deeply under, the anæsthetic is withheld too long, and the operation is interrupted by an attack of coughing or vomiting.

Before considering the matter in detail let us see what is the proportion of patients who are actually sick and whether from observing their behaviour during and after anæsthesia we get any hint towards the prevention of after-sickness. For this purpose I have notes of a consecutive series of 572 cases. These I have either personally observed throughout or have had accurate accounts of their behaviour after the anesthetic from observation carefully made by the nurse in charge. The cases include both hospital and private patients, the great majority of the former being operated on at St. George's Hospital and a few at the Grosvenor Hos. pital for Women and Children. They may for the present purpose be divided into three groups. There are (1) those patients who do not vomit at all; (2) those who vomit only before return of consciousness-these if questioned say they are not sick after their anxsthetic; and (3) those who vomit after consciousness has returned, or both before and after. Patients differ greatly as to the length of time that elapses before consciousness returns. As a rule, of course, the longer the administration-i.e., the more of the anæsthetic absorbedthe longer is the interval before walefulness returns. But whereas some patients will sleep for hours after a short administration others will begin to come round within five minutes of the end of an administration lasting over an hour. Generally speaking, if the whole administration has not lasted much more than half an hour patients begin to come round or to vomit within five minutes. And this is what we should aim at. When a patient is safely back in bed the sooner he begins to come round the better. If he remains comatose for a long time it generally means that he has had an unnecessary amount of anæsthetic and will probably be sick in proportion. Those of class (1) have voluntary movements of the head from side to side, then more or less sensible and articulate speech, and gradually become more awake, or else lie back and sleep again, waking up sensible an hour or so later. In patients of the second class consciousness generally begins to return very shortly after the vomiting; there are sometimes two or three bouts of vomiting before the patient is conscious. In patients of class (3) the number of times that vomiting is repeated varies greatly. Some will have four or five attacks during the 12 or even 24 hours that follow the operation. After an operation at 2 P.M. it not unfrequently happens that a patient who has come round and feels comfortable enough wakes up in the middle of the night and vomits, this being very likely his one and only attack. Such an attack may certainly be expected if unsuitable food is given, even eight or nine hours after return of consciousness.

The proportion of patients free from after-sickness.-Of the 572 patients there was no after-sickness in 143 , exactly a quarter of the whole number. In the remaining 429 aftersickness preceded the return of consciousness and may therefore be disregarded from the patient's point of view in 50 cases. So far therefore as the patient's comfort is concerned very nearly one third of all the cases (193) may be regarded as free from after-sickness.

The nature of the patient.-Can we say beforehand whether or not a particular patient will be sick after taking an anæsthetic? I think we cannot, although when we give him the anæsthetic we can generally tell before the end of the operation how he will behave afterwards in this respect. It is at present within certain limits impossible to say why of two patients who undergo the same operation under the same anæsthetic administered by the same hand one will be sick and the other not. It depends on what, for want of more precise knowledge, we call idiosyncrasy. Just as one man has "a head for wine" while another is easily intoxicated, 